\title{
sciendo
}

\section{Job Burnout and Counterproductive Work Behaviour of the Jordanian Bank Employees}

\author{
Tareq LUBBADEH
}

University of Pécs, Faculty of Business and Economics, Pécs, Hungary, Tareq.lubbadeh@yahoo.com

\begin{abstract}
Background/Purpose: This study investigated the relationship between job burnout and counterproductive work behavior (CWB) among 307 employees drawn from various banks within Jordan. This study also examined the levels of job burnout and CWB with regard to gender, age, marital status, and education.

Methodology: For data collection, the convenience sampling method is utilized to survey frontline bank employees. The Oldenburg Burnout Inventory scale, which assesses exhaustion, disengagement, and the CWB scale from the Individual Work Performance Questionnaire (IWPQ), were used for data collection. The data were analyzed using the Statistical Package for Social Science 25.0.

Results: The study results suggest that there is a significant positive relationship between job burnout two dimensions and CWB. The research also shows that age, education, and marital status affect both job burnout and CWB. Nevertheless, gender was found to have a significant effect only on the disengagement dimension of job burnout. Further, the study implies that exhaustion and disengagement are vital predictors influencing CWB.

Conclusion: With regard to the results, the phenomena of job burnout provide the means that can provoke deviant behavior in the workplace.
\end{abstract}

Keywords: Job burnout, Exhaustion, Counterproductive work behavior, Bank employees, OLBI

\section{Introduction}

Banking industries have undergone a number of dramatic changes in management and structure over the last few years, such as introducing new technology and methods of structuring the process, which affected the working conditions and the employees' daily lives. The financial industry now is more customer-oriented, offering convenience, quality of service, and creative service. Bank workers perform an essential role in providing high service quality. These advancements generate a great deal of stress for those who work in the banking sector (Giorgi et al., 2017). The banking sector jobs have been highly valued out from a social, financial, and economic viewpoint. In recent years, nonetheless, this situation has changed drastically for many reasons; for example, the size of these financial institutions has shrunk, resulting in massive layoffs, increased pressure, increased demand and competition in daily work, or consumer hostility towards employees who are blamed for selling financial products that lead to large losses (Amigo et al., 2014). These changes created an environment of sensitivity among the bank's staff, which sharpened their work context, and individually reinforced the tendency to feel overwhelmed, and thus, counterproductive work behavior.

Originally, job burnout was conceived as being primarily related to professions of the human service (e.g., physicians, nurses, and teachers), as they are presumed to be most vulnerable to emotional stimuli because their roles require a great deal of interaction with people. Nevertheless, more recent research has shown that job burnout

Received: 12th July 2020; revised: 29th November 2020; accepted: 22th December 2020 
is not constrained undecidedly to these occupations but also expanded to other professions (e.g., managers, bank employees, and HR workers) (Demerouti et al., 2001; Maslach, 2006; Prusik \& Szulawski, 2019).

Job burnout is described here as a consequence of constant exposure to work-related stress caused by high job requirements and insufficient job resources and consists of two fundamental dimensions exhaustion and disengagement from work (Demerouti et al., 2014). Exhaustion is described as a response to the intense physical, affective, and cognitive strain due to increased exposure to specific demands at work. Disengagement involves distancing oneself from work and developing a negative attitude regarding the work context due to the inadequacy in the job resources (Demerouti et al., 2001). Job burnout has been associated with various adverse individual and organizational outcomes. For instance, burnout employees have a higher intention to leave their jobs (Maslach et al., 2001; Vaamonde et al., 2018; Wen et al., 2020), absenteeism (Dyrbye et al., 2019; Lubbadeh, 2020), job attitudes (Laschinger \& Fida, 2014), lower task and contextual job performance (Bakker et al., 2004; Demerouti et al., 2014), and counterproductive work behavior (CWB) (Ugwu et al., 2017; Makhdoom et al., 2019). Job burnout dimensions were also linked with numerous health and mental problems such as headaches, cardiovascular problems, insomnia, and depression (Armon, 2009; Leiter et al., 2013).

Accordingly, job burnout may influence the organizational outcomes negatively by counterproductive work behaviors (CWB) - refers to "voluntary behavior that harms the well-being of the organization." (Rotundo \& Sackett, 2002, p. 69). Damaging an organization's property, withdrawal, gossiping, complaining, insulting others, harassing behaviors, and theft are examples of CWB. These behaviors are damaging to the organization either by impacting its activity or assets directly or negatively influencing the employees in ways that decrease their efficacy. Counterproductive work behaviors have substantial financial consequences for the organizations; according to Bennett and Robinson (2000), $33 \%$ to $75 \%$ of all U.S. employees have been involved in different forms of Workplace deviance behaviors. Additionally, the predicted cost of CWB for organizations exceeds $\$ 1$ trillion distributed on deviation behaviors such as theft, violence in the workplace, and fraudulent activities (Banks et al., 2012; Smoktunowicz et al., 2015). CWB is not only costly for the organizations, but further has various adverse outcomes for employees. For example, employees who are a victim of CWB (e.g., bullying and harassment) can lead to reduced job satisfaction, prolonged stress, and quitting intentions, among others (Berry et al., 2012). Considering such high costs, both for organizations and workers, it is crucial for company leaders to consider and anticipate who is most likely to participate in such behavior (Cohen, 2016).
In light of this, the main objectives of the present study are to investigate the relationship between job burnout and counterproductive work behavior (CWB) among bank employees by analyzing their opinions. The research also explored several determinants, such as gender, age, marital status, and education, and their influences on the relationship between job burnout and CWB. This study presents research contributions in various fundamental ways. First, this investigation continues previous research on the relationship between job burnout and CWB. Second, despite the presence of vast literature on job burnout and CWB, these relationships have not been examined much in the banking sector. Therefore, examining these relationships may increase managerial awareness of the causes of job burnout, $\mathrm{CWB}$, and its negative impact on organizations and individuals, as well as to advance prevention and protection strategies. Third, in the study, job burnout and CWB were studied in the Jordanian setting, which is rarely examined. It is necessary to investigate job burnout and CWB in different contexts to see whether the indicators of this behavior act in other societies differently. Finally, the current study by examining job burnout and its relationship to the CWB of the front office officers in Jordan's banking sector contributes to the field of HRM.

The rest of the article is displayed as follows. Chapter 2 outlines the literature review, whereas Chapter 3 describes the research hypothesis. In Chapter 4 , the study methodology is specified, while Chapter 5 displays the study results - finally, Chapter 6 closing the paper with a Conclusion, contribution, and possible future research studies.

\section{Literature Review}

\subsection{Theoretical overview}

CWB is an essential subject to study because it carries negative implications and consequences for organizations and employees themselves (Banks et al., 2012). For example, deviant work behaviors destabilize the organization's internal performance and create high costs due to lost productivity. These behaviors may also directly affect employee performance evaluation and career development (De Clercq et al., 2019). CWB is composed of intentional behavior displayed by employees intended to harm organizations and their stakeholders (e.g., customers, co-workers, and supervisors) (Spector \& Fox, 2005). Sackett and DeVore (2002) describe CWB as deliberate behavior by an organization member, which the organization deems to be contrary to its legitimate interests. CWB has been abstracted in several ways, such as aggression (Spector et al., 2006) and workplace deviance (Robinson \& Bennett, 1995). Deviance is a distinct form of CWB; Robinson and Bennett (1995) defined it as "voluntary behavior that vi- 
olates significant organizational norms and, in so doing, threatens the well-being of an organization, its members, or both."(p 556). Bennett and Robinson (2000) distinguished between two types of deviance, organizational deviance directed at the organization (e.g., withholding effort) while the other interpersonal deviance is directed at individuals working in the organization (e.g., behaving indecently toward co-workers).

The stressor-emotion model of CWB (Spector \& Fox, 2005) may be used to illustrate the process that contributes to CWB. The model suggests that stressful work conditions may provoke the employees' negative feelings and their perception of limited control over the situation, which in turn contributes to CWB. According to their model, CWB reflects the employees' responses to a stressful work environment as a way to deal with the impediment arising from work. In support of this line of thinking, using the bank employees as a case (Cruz-Santiago et al., 2020) affirmed that employees working in the banking sector experience stress, overburdened, work routine, and disappointment with their work creating emotional, and physical strain which can lead to job burnout. In fact, there is much literature indicating how stressful and challenging is that working in the banking sector can be. For example, working in the banking sector has the distinction of being one of the most challenging and demanding business environments, with excessive work-load, ambiguity, unattainable job resources, and constant contact with clients (Giorgi et al., 2017; Rehman et al., 2015; Socorro et al., 2016). These make the banking sector workers more susceptible to job burnout's adverse influence and, by extension, CWB.

The Job Demand-Resources (JD-R) model (Demerouti et al., 2001) can illustrate how job burnout can lead to CWB. The (JD-R) model assumes that job characteristics can be classified into two classes (job demands and job resources) associated with job burnout dimensions exhaustion and disengagement. Job demands refer to work factors such as (physical work-load, time pressure, and recipient interaction) that require constant energy from the employee; hence, if the job demands are remarkably high or inadequately designed could point to the exhaustion dimension. Conversely, job resources associate with factors such as (rewards, safety at work, career opportunities, and support), which are required to deal with job demands, the absence of job resources could point to job burnout's disengagement dimension (Demerouti et al., 2001, 2005). Based on the JD-R model, we reason that high job requirements accompanied by a scarcity of work resources can strengthen the employees' exhaustion and disengagement, which produces the necessary levels of fatigue and withdrawal for CWB to develop.

\subsection{Job Burnout and CWB}

The intriguing relationship between job burnout and counterproductive work behavior (CWB) has been explored in various occupational groups, and different explanations for the relationship were advanced. For example, Mulki, Jaramillo, and Locander (2006) found that emotionally exhausted employees become less satisfied with their jobs and become less devoted to the organization, which leads to deviant behaviors. However, the researchers only investigated the relationship between emotional exhaustion and workplace deviance. In comparison, Liang and Hsieh (2007) investigated the relationship between job burnout and workplace deviance behavior (as part of the work performance) of 303 Taiwanese flight attendants. The authors hypothesized a positive relationship between the job burnout dimensions (emotional exhaustion, depersonalization, reduced personal accomplishment) and workplace deviance. The study found that only job burnout dimensions depersonalization was a significant predictor of deviant behavior in the workplace. That being said, the researchers observed no meaningful relationship between the other two dimensions of job burnout and the employees' deviant behavior. The authors argued that a lack of emotional resources and high emotional demands at work could lead to emotional exhaustion then depersonalization, which may lead to deviant behavior in the workplace. In a comparable study that examined the relationship between job burnout and CWB (Bolton et al., 2011) found that employees who reported being depersonalized were more prone to display CWB. However, they explained that exhausting the employee's emotional resources could lead to an increase in his sense of depersonalization, which in turn leads to an increased probability of the employee to participate in behaviors that harm the organization.

Banks et al. (2012) explore the relationship between emotional exhaustion and CWB targeted at the individual (CWB-I) and the organization (CWB-O) among a sample of bank employees working in South Korea. The study reported a significant positive relationship between emotional exhaustion and CWB through a decline in the employees' commitment toward the organization. The authors note that employees' attitudes and expectations directly impact their behaviors rather than job stressors and personal strains. Employees become emotionally exhausted, their exchange with the organization becomes less favorable, and they are more likely to lower their overall levels of commitment, which can increase CWB. Moreover, Uchenna (2013) examined the significance of perceived organizational support, job burnout, and age on counterproductive work activity between employees employed in the hospitality and healthcare sectors. The study found that there was a significant negative relationship between perceived organizational support and CWB. The study 
also conveyed that employees who reported job burnout demonstrated a higher tendency to participate in counterproductive work behavior than employees who did not report job burnout. The study as well found that age has no significant influence on displaying CWB between employees. The results indicate that employees were more willing to display harmful behaviors if they realized that the support they received from the organization was limited. In contrast, when the employees perceive that the organization's support is favorable and discretionary, they were less prone to engage in CWBs (Uchenna, 2013).

In their study, Smoktunowicz et al. (2015) examined the relationship between job burnout two dimensions (exhaustion and disengagement) and CWB among 607 police officers using the job demands, control, support model, and the conservation of resources model (COR). The study found that job burnout moderates the relationship between job demands and CWB. However, they explained that the relationship between job burnout and deviant behavior might be based on the chain reactions from job demands to CWBs. High job demands in the workplace may limit the employees' job resources and lead to exhaustion and disengagement from work. In response, the employees may channel their work hours to CWBs rather than behaviors that follow the organization's interest in maintaining their resources.

With respect to healthcare professionals, Ugwu et al. (2017) investigated the relationship between job burnout and CWB among 401 nurses working in several hospitals in Nigeria. The uniqueness of this study is that it found a relationship between the three job burnout dimensions (emotional exhaustion, depersonalization, and personal accomplishment) and counterproductive work behavior. The authors concluded that stressful work environments with long hours of work could deplete nurses' emotional resources and lead them to experience disconnection from their work and patients, thus increasing CWB opportunities. In their research, Shkoler and Tziner (2017) found in a sample drawing from different sectors that burning out employees engage in more misbehavior (WMBs) as coping mechanisms for developing a sense of emotional stability subjugating negative feelings at work. More recently, Lebrón et al. (2018) found that employees who described being emotionally exhausted were more likely to display organizational deviance behavior. According to the authors, emotionally depleted employees may think that they do not receive adequate compensation for their work. As a consequence, they may try to rectify the situation by engaging in organizational deviations.

In a related study that investigated the relationship between job burnout and different forms of CWB (withdrawal, abuse, and sabotage), Makhdoom, Atta, and Malik (2019) found that reduced personal accomplishment and depersonalization significantly predict withdrawal and sabotage. However, the researchers found that emotional exhaustion was not a significant predictor of sabotage and withdrawal. The researcher justifies these results based on the suggestion of Maslach et al. (2001) that emotional exhaustion is more related to the social conflict that might result in abuse instead of the lack of resources that might result in sabotaging the organization's assets.

The majority of the previous studies that investigated the relationship between job burnout and CWB focused on different occupations. Nevertheless, studies among bank employees are limited in general and, expressly, in the Jordanian context.

Job burnout and CWB dramatically influence the type of work in which the employee is involved. The relationship between job burnout and CWB is substantial. Overall, job burnout can lead to a higher tendency by the employees to engage in CWBs.

\section{Research hypotheses}

According to the hypothetical ground, the following research hypotheses were formulated. Hypothesis H1 was formed according to the Job Demand Resources Framework (JD-R) (Demerouti et al., 2001), in which high job requirements followed by lack of labor resources can lead to intense employees' exhaustion and disengagement from work, which could create the necessary environment for CWB to develop.

- H1: There is a statistically significant relationship between job burnout and counterproductive work behavior among Jordanian bank employees.

Hypotheses H2, H3, H4, H5 were formed based on the findings of Amigo et al. (2014), who stated that age and gender are essential influencer factors in job burnout and the results of Tarcan et al. (2017) who affirmed that education, marital status, and occupation affect job burnout. The results of Cruz-Santiago et al. (2020) showed that gender affects job burnout. According to Bolton et al. (2011), gender and age are significant factors regarding CWB. Ugwu et al. (2017) summarized that gender and age are influencing predictors of CWB. The findings of De Clercq et al. (2019) who reported that female employees are less likely to engage in CWB than their male counterparts.

- H2: There will be a statistically significant infl ence of gender on job burnout and CWB.

- H3: There will be a statistically significant infl ence of age on job burnout and CWB.

- H4: There will be a statistically significant infl ence of marital status on job burnout and CWB.

- H5: There will be a statistically significant infl ence of education on job burnout and CWB. 


\section{Methodology}

\subsection{Participants and Procedures}

Participants in the study consisted of frontline bank employees working in different commercial banks operating in Jordan. Participants were confined to front office employees of the banks that interact instantly with customers in their jobs. Therefore, the sample includes employees who were in the front office, in charge of customer services, sales, and money exchange services (tellers). Banks were chosen based on two criteria, the first of which is the number of employees (more than 100 employees); accordingly, 17 banks were targeted in the Kingdom of Jordan. The second criterion was the bank's approval of distributing the questionnaire among the employees; thus, seven of the 17 banks agreed to participate in the field survey. This study used a convenience sampling technique to collect the data. Therefore, the final sample for the data analysis featured 307 bank employees $(n=307)$.

Participants in the study were invited through bank representatives or by e-mail, or by visiting different bank branches. The data have been finalized without missing data incidence. A link to an online survey was provided to the prospective study participants in several commercial banks operating in Jordan (including Jordanian and foreign commercial banks).

The survey consisted of the demographics (gender, age, gender, age, marital status, and educational levels), job burnout, and CWB (IWQP). Bank employees expressed their consent to participate in the study by completing the questionnaire. The research was voluntary, and participants were not offered compensations. Data were collected as part of an ongoing Ph.D. dissertation at the University of Pécs. The data were collected during the emergency state in Jordan related to (COVID-19) and took around three weeks from the beginning of May until the beginning of June 2020 .

The study sample was approximately equal concerning gender $157(51.1 \%)$ of whom were male, and $150(48.3 \%)$ of whom were female, while $131(42.7 \%)$ were single, 145 $(47.2 \%)$ were married, and only $31(10.1 \%)$ were divorced. The minimum working experience in the current bank was 1 , with a maximum of 25 years $(\mathrm{M}=6.5, \mathrm{SD}=4.8)$. All of the participants in the study were well educated; 14 (4.6\%) of the respondents are holding a diploma degree, 204 $(66.4 \%)$ with a bachelor's degree, and $75(24.4 \%)$ of the participants holding a master's degree. Additionally, there were $14(4.6 \%)$ employees with a Ph.D. Concerning the age groups, $184(59.9 \%)$ of the participants were in the age group 20-34 (young), $96(31.3 \%)$ were in the age group 35-49 (middle-aged), and 27 (8.8\%) were aging (50 and older).

\subsection{Measures}

In order to assess job burnout and counterproductive work behavior, pre-existing, and validated measures were used. The survey also comprised questions about demographics (gender, age, marital status, and educational levels).

Job burnout was assessed using the Oldenburg Burnout Inventory (OLBI) English version (Demerouti et al., 2003, 2010). The instrument consists of two subscales, exhaustion and disengagement; each subscale consists of four questions worded positively and four questions worded negatively. Exhaustion was measured with eight items (e.g., after working, I have enough energy for my leisure activities), reversed items (e.g., There are days when I feel tired before I arrive at work). Disengagement was measured with eight items (e.g., I find my work to be a positive challenge), reversed items (e.g., Lately, I tend to think less at work and do my job almost mechanically). Response to the 16 items instrument is provided using a four-point scale, ranging from 1 to 4 (Strongly agree to strongly disagree).

The construct convergent validity of the (OLBI) has been confirmed in previous validation studies in various countries and professions (Halbesleben \& Demerouti, 2005; Al-Asadi et al., 2018). These investigations certainly proved that the structure of two factors (exhaustion and disengagement) as the underlying factors fits better with different occupational groups' data than alternative factor structures. The variables' internal consistencies were satisfactory for exhaustion (Cronbach's alpha $=0.731$ ) and disengagement (Cronbach's alpha $=0.730$ ). For computing the average score for each of the two subscales, the negative items were reversed when necessary so that the higher score indicates more exhaustion or disengagement. In further analysis, we used the average scores.

Counterproductive work behaviors (CWB)- was measured via a five-item scale developed by (Koopmans, 2015; Koopmans et al., 2016) (The Individual Work Performance Questionnaire (IWQP)) English version. The five-item scale measures counterproductive work behavior aimed at the personal and the organizational levels (e.g., I focused on the negative aspects of situation at work instead of the positive aspects). The scale had a recall period of 3 months, and participants answered each item on a five-point scale $(0=$ never, $1=$ seldom, $2=$ sometimes, $3=$ quite often, $4=$ often). The construct validity and reliability of the (IWQP) were also established in earlier validation studies in various countries and professions (Koopmans et al., 2016; Jakada et al., 2020). The internal consistency of the CWB was excellent (Cronbach's alpha $=0.85$ ). The means of the counterproductive work behavior scale can be calculated by summing the scores on the scale items and dividing the total by the number of items in the scale, 
higher scores indicating higher counterproductive work behavior (Koopmans, 2015). We used the average scores of the scale in the analysis. The scale items for all variables are presented in the Appendix.

\subsection{Data analysis}

The data were analyzed using the Statistical Package for Social Science (IBM-SPSS) version 25.0. The data obtained from the questionnaires were first transformed to excel and codded, then transformed into the SPSS program; significance tests of the difference between the means of the groups and the necessary descriptive statistics were performed to verify alignment with the study's aims. Additionally, the Pearson correlation (r) test was used to ascertain the correlation between studied constructs. The parametric t-test was used to test hypothesis $\mathrm{H} 2$ regarding the influence of gender on job burnout and CWB levels. The parametric one-way ANOVA and the Bonferroni post hoc test was used to test hypothesis $\mathrm{H} 3$ - H5 about the influence of age, marital status, and education on job burnout and CWB levels. A hierarchal regression (with gender, age, marital status, and education entered as control varia- bles) was used to test hypothesis $\mathrm{H} 1$ about the relationship between job burnout and CWB.

\section{Results}

A preliminary examination was carried to assure no violation of the assumption of normality; the study variables were normally distributed according to the examination of histograms and Skewness and kurtosis values falling within the acceptable range of \pm 1.0 . Also, no potential multivariate outliers were identified based on the analysis of the Mahalanobis distances.

Table 1 presents a summary of descriptive statistics for the variables and their correlations. The level of exhaustion was (2.60), disengagement (2.62), and counterproductive work behavior (1.97) across the sample. All constructs were positively intercorrelated (job burnout and CWB). It is observed that there a significant positive correlation between the two dimensions of job burnout. The two job burnout dimensions: exhaustion and disengagement, were significantly and positively correlated with the bank employees' counterproductive work behavior (CWB).

Table 1: The Summary of Descriptive Statistics \& Correlations, $N=307$

\begin{tabular}{|cl|l|l|l|l|l|}
\hline Variable & $\mathrm{M}$ & $\mathrm{SD}$ & 1 & 2 & 3 \\
\hline 1. & Exhaustion & 2.60 & 0.52 & 1 & & \\
\hline 2. Disengagement & 2.62 & 0.57 & $0.731^{* *}$ & 1 & \\
\hline 3. CWB & 1.97 & 1.01 & $0.473^{* *}$ & $0.456^{* *}$ & 1 \\
\hline
\end{tabular}

Note: $\mathrm{N}=307, * * \mathrm{p}<0.01$ (two-tailed)

Table 2: Job burnout and counterproductive work behavior according to gender

\begin{tabular}{|l|l|l|l|l|l|l|}
\hline \multirow{2}{*}{ Job burnout and CWB } & Gender & $\mathrm{n}$ & $\mathrm{M}$ & $\mathrm{S} D$ & $t$ & $p$ \\
\hline \multirow{2}{*}{ Exhaustion } & Male & 157 & 2.54 & 0.49 & -1.937 & \multirow{2}{*}{0.54} \\
\cline { 2 - 6 } & Female & 150 & 2.66 & 0.58 & & \\
\hline \multirow{2}{*}{ CWB } & Male & 157 & 2.55 & 0.50 & -2.043 & \multirow{2}{*}{$0.043^{*}$} \\
\cline { 2 - 5 } & Female & 150 & 2.68 & 0.60 & & \\
\hline
\end{tabular}

Note: $\mathrm{N}=307$. Gender was coded $0=$ male, $1=$ female. ${ }^{*} \mathrm{p}<0.05$ (two-tailed). 
Table 2 shows the comparison of job burnout and counterproductive work behavior based on gender. The disengagement dimension of job burnout had a significant difference between males and females employees. In terms of disengagement, the average burnout scores for female bank workers were more prominent than those of their male peers. Moreover, the average score of females was higher than their male peers in counterproductive work behavior. However, gender differences in counterproductive behavior scores were not statistically significant. Therefore, we concluded that while gender influences burnout levels, it does not substantially influence counterproductive work behavior levels. Based on the results, H2: There will be a statistically significant influence of gender on job burnout, and CWB can only be partially confirmed.

Table 3 presents the comparison of job burnout and counterproductive work behavior by age. Although exhaustion dimension scores differ significantly depending on age, in contrast, disengagement scores were not significantly affected by age. The exhaustion score among the aging group was higher than the score for the young and middle-aged groups. We also note that the exhaustion scores increases with the increase in the age group. Similarly to the Exhaustion score results, the counterproductive work behavior scores were statistically significant, and the CWB scores among the aging group were higher than the score of the other two groups. The post hoc test indicates, the aging group (50 years and older) showed higher exhaustion than the young age and the middle age groups. Concerning $\mathrm{CWB}$, the aging group showed higher CWB than the young and the middle age groups. We have accordingly reasoned that age is an essential factor that influenced both exhaustion and CWB. Based on the results, the hypothesis $\mathrm{H} 3$ : that there will be a statistically significant influence of age on job burnout and CWB, can only be partially confirmed.

Table 3: Job burnout and counterproductive work behavior based on age

\begin{tabular}{|c|c|c|c|c|c|c|}
\hline Job burnout and CWB & Age & $\mathrm{n}$ & Mean & $S D$ & $F$ & $p$ \\
\hline \multirow[t]{3}{*}{ Exhaustion } & 20-34 years & 184 & 2.55 & 0.51 & \multirow[t]{3}{*}{4.412} & \multirow[t]{3}{*}{$0.013^{*}$} \\
\hline & $35-49$ years & 96 & 2.60 & 0.51 & & \\
\hline & 50 years and older & 27 & 2.88 & 0.60 & & \\
\hline \multirow[t]{3}{*}{ Disengagement } & $20-34$ years & 184 & 2.57 & 0.56 & \multirow[t]{3}{*}{2.854} & \multirow[t]{3}{*}{0.059} \\
\hline & $35-49$ years & 96 & 2.65 & 0.56 & & \\
\hline & 50 years and older & 27 & 2.83 & 0.65 & & \\
\hline \multirow[t]{3}{*}{ CWB } & $20-34$ years & 184 & 1.93 & 1.04 & \multirow[t]{3}{*}{6.712} & \multirow[t]{3}{*}{$0.001^{*}$} \\
\hline & $35-49$ years & 96 & 1.88 & 0.89 & & \\
\hline & 50 years and older & 27 & 1.97 & 1.08 & & \\
\hline
\end{tabular}

Note: Age was coded $0=20-34$ years, $1=35-49$ years, $2=50$ years and older. ${ }^{*} \mathrm{p}<0.05$

Table 4: Job burnout and counterproductive work behavior based on marital status

\begin{tabular}{|c|c|c|c|c|c|c|}
\hline Job burnout and CWB & Marital status & $n$ & M & $S D$ & $F$ & $p$ \\
\hline \multirow[t]{3}{*}{ Exhaustion } & Single & 131 & 2.50 & 0.532 & \multirow[t]{3}{*}{6.029} & \multirow[t]{3}{*}{$0.003 *$} \\
\hline & Married & 145 & 2.63 & 0.531 & & \\
\hline & Divorced & 31 & 2.85 & 0.571 & & \\
\hline \multirow[t]{3}{*}{ Disengagement } & Single & 131 & 2.55 & 0.513 & \multirow[t]{3}{*}{3.004} & \multirow[t]{3}{*}{0.051} \\
\hline & Married & 145 & 2.64 & 0.559 & & \\
\hline & Divorced & 31 & 2.81 & 0.680 & & \\
\hline \multirow[t]{3}{*}{ CWB } & Single & 131 & 1.89 & 0.982 & \multirow[t]{3}{*}{7.513} & \multirow[t]{3}{*}{$0.001 *$} \\
\hline & Married & 145 & 1.91 & 0.981 & & \\
\hline & Divorced & 31 & 2.62 & 0.992 & & \\
\hline
\end{tabular}

Note: Marital status was coded $0=$ Single, $1=$ Married, $2=$ Divorced. $* p<0.05$. 
A comparison of job burnout and counterproductive behavior based on marital status are presented in Table 4 . There was a significant variation between marital status and the exhaustion dimension, while the disengagement scores did not significantly differ according to marital status. Job burnout scores among divorced employees were higher than those for single and married employees concerning burnout's exhaustion dimension. Similarly, the differences in the counterproductive work behavior scores according to marital status were also statistically significant, and the CWB scores among divorced employees were higher than the scores for their co-workers. The post hoc test indicates that divorced employees score higher on the exhaustion scale than single employees. With respect to counterproductive work behavior, divorced employees score higher on the CWB than married and unmarried employees. Thus, we can infer that marital status was a significant variable as it influenced exhaustion and CWB. H4: stating that there will be a statistically significant influence of marital status on job burnout, and CWB has been partially confirmed.

The results of the comparison of job burnout and coun- terproductive work behavior, according to educational levels, are displayed in Table 5. The findings indicate that the level of education significantly influences job burnout and CWB. Job burnout scores of bank employees with a Ph.D. degree were higher than the other employees. Notably, we can see that as the educational attainment increased, the scores of exhaustion and disengagement also increased. According to education levels, the differences in exhaustion and disengagement were statistically significant. There were also substantial differences in CWB scores for educational status. The post hoc analysis results showed that employees with bachelor's degrees were less affected by exhaustion than the employees with master's and $\mathrm{Ph} . \mathrm{D}$. degrees. Also, employees with bachelor's degrees exhibit less disengagement than the employees with master's and Ph.D. degrees. Concerning the CWB, employees with Ph.D. degrees display more deviant behavior at work than the employees with bachelor's and master's degrees. Therefore, hypothesis $\mathrm{H} 4$ that there will be a statistically significant influence of education on job burnout and CWB is fully supported.

Table 5: Job burnout and counterproductive work behavior based on educational levels

\begin{tabular}{|c|c|c|c|c|c|c|c|c|c|c|}
\hline \multirow[t]{2}{*}{$\begin{array}{l}\text { Job burnout and } \\
\text { CWB }\end{array}$} & \multicolumn{2}{|c|}{ Diploma $(n=14)$} & \multicolumn{2}{|c|}{$\begin{array}{l}\text { Bachelor degree } \\
(n=204)\end{array}$} & \multicolumn{2}{|c|}{$\begin{array}{l}\text { Master degree } \\
(n=75)\end{array}$} & \multicolumn{2}{|c|}{$\begin{array}{l}\text { PhD degree } \\
(n=14)\end{array}$} & \multirow[t]{2}{*}{$F$} & \multirow[t]{2}{*}{$p$} \\
\hline & Mean & SD & Mean & SD & Mean & SD & Mean & SD & & \\
\hline Exhaustion & 2.56 & 0.43 & 2.51 & 0.52 & 2.77 & 0.52 & 3.03 & 0.69 & 7.756 & $0.000 *$ \\
\hline Disengagement & 2.53 & 0.62 & 2.54 & 0.50 & 2.77 & 0.61 & 3.00 & 0.68 & 5.402 & $0.001 *$ \\
\hline CWB & 2.24 & 1.02 & 1.82 & 0.96 & 2.16 & 0.99 & 2.95 & 0.89 & 7.695 & $0.000 *$ \\
\hline
\end{tabular}

Note. Educational levels was coded $0=$ Diploma, $1=$ Bachelor, $2=$ Master, $\mathrm{PhD}=3,{ }^{*} \mathrm{p}<0.05$.

The hierarchical regression model was used, where the dependent variable was CWB, while the explanatory variables included in the model were job burnout dimensions (exhaustion, disengagement). In the analyses, control variables, including gender, age, marital status, and education, were inscribed in Step 1. The two dimensions of job burnout were entered at Step 2 together rather than entered step by step. The results are presented in Table 6 . The regression results showed that the overall regression model significantly predicted CWB, $[\mathrm{F}(6,300)=17.181, \mathrm{p}$ $<0.001$ ], and that over $26 \%$ of the variance of a dependent variable is explained by the regression model $(\mathrm{R}$ square $=$ 0.263 ). The values of the variance inflation factor (VIF) were below 2 , and the tolerance values were above 0.10 , which indicates that there was no concern regarding the multicollinearity in the regression model (Kleinbaum et al., 1988).

In the first step, the sociodemographic variables: gender, age, marital status, and education have entered; the variables jointly accounted for $5.6 \%$ variance in CWB with only marital status $(\beta=0.140, p<0.05)$ and education ( $\beta=0.185, p<0.001)$ emerged as a significant predictor of CWB. After controlling the sociodemographic variables and introducing exhaustion and disengagement into the regression equation (step 2), the amount of variance explained increased significantly [R squared change $=0.207$, $\mathrm{p}<0.001]$. Results also reveal that the impact of exhaustion on the employees' CWB is, as expected, positive. The higher the exhaustion, the higher on average, the employees' $C W B$; the impact is significant $(\beta=0.278, p<0.001$ ). The disengagement dimension of job burnout also proved to have a significant and positive impact on employees' CWB $(\beta=0.236, p<0.01)$; employees who perceive a higher level of disengagement are more likely to engage in CWB behavior at work. Overall, hypothesis H1, which stated that there is a statistically significant relationship between job burnout and counterproductive work behavior among Jordanian bank employees, was supported. 
Table 6: Hierarchical Regression Analysis results

\begin{tabular}{|c|c|c|c|c|c|c|}
\hline & \multicolumn{3}{|c|}{ Step 1} & \multicolumn{3}{|c|}{ Step 2} \\
\hline & $B$ & $S E$ & $t$ & B & $S E$ & $t$ \\
\hline Constant & 1.467 & 0.150 & $9.802 * * *$ & -0.621 & 0.263 & $-2.357 * * *$ \\
\hline \multicolumn{7}{|l|}{ Sociodemographic } \\
\hline 1. Gender & -0.014 & .112 & -.127 & -.125 & 0.100 & -1.244 \\
\hline 2. Age & -0.028 & .111 & -.249 & 0.003 & 0.099 & 0.030 \\
\hline 3. Marital status & 0.216 & .104 & $2.085^{*}$ & .093 & 0.093 & 0.999 \\
\hline 4. Education & 0.298 & .099 & $3.024^{* *}$ & 0.111 & 0.090 & 1.240 \\
\hline \multicolumn{7}{|l|}{ Main effects } \\
\hline 5. Exhaustion & & & & 0.513 & 0.136 & $3.759 * * *$ \\
\hline 6. Disengagement & & & & 0.426 & 0.131 & $3.243^{* *}$ \\
\hline $\mathrm{F}$ & \multicolumn{3}{|c|}{$4.442 * *(4,302)$} & \multicolumn{3}{|c|}{$17.818^{* * *}(6,300)$} \\
\hline F change & \multicolumn{3}{|c|}{$4.442 * *(4,302)$} & \multicolumn{3}{|c|}{$42.150 * * *(2,300)$} \\
\hline R2 & \multicolumn{3}{|l|}{$0.056^{* *}$} & \multicolumn{3}{|c|}{$0.263 * * *$} \\
\hline$\Delta \mathrm{R} 2$ & \multicolumn{3}{|l|}{$0.056 * *$} & \multicolumn{3}{|c|}{$0.207 * * *$} \\
\hline Adj. R2 & \multicolumn{3}{|l|}{$0.043 * *$} & \multicolumn{3}{|c|}{$0.248 * * *$} \\
\hline
\end{tabular}

Note. $\mathrm{N}=307,{ }^{*} \mathrm{p}<0.05, * * \mathrm{p}<0.01, * * * \mathrm{p}<0.001$.

\section{Discussion and conclusion}

This current study investigating the relationship between job burnout and counterproductive work behavior in Jordan's banking sector is of considerable significance because, firstly, the banking sector is one of the most significant sectors in Jordan and contributes largely to its economy. Moreover, the number of studies that investigated the relationship between job burnout and CWB with respect to bank employees is limited, where the majority focused on human service employees.

To begin with, the study results indicate that bank employees are suffering from job burnout and high levels of counterproductive work behavior. We also notice that job burnout and CWB are influenced by age, marital status, and education levels, but CWB is not significantly affected by gender.

The study shows that there are significant gender differences in job burnout (disengagement) levels. Female employees experience higher disengagement levels than their male co-workers, as reported in previous studies (Lackritz, 2004; Amigo et al., 2014; Tarcan et al., 2017). One explanation that can be devoted to this result is that in Jordanian society, women are still performing the majority of housework in addition to their job requirements, which may direct to an increased sense of job burnout. In comparison, no significant gender-based differences in
CWB levels, which indicate that bank employees engage in counterproductive work behaviors regardless of gender, which consists of (Baysal et al., 2020), who stated that the gender variable does not create a variation in CWB. Unlike the results of the present study (Ugwu et al., 2017) reported that gender negatively predicts CWB and the outcomes of (De Clercq et al., 2019), who noted that male employees are more prone to take part in CWB than their female co-workers.

Concerning age, the results show that exhaustion levels significantly vary according to age. With respect to exhaustion, employees in the aging group (50 years and older) experience more exhaustion than the other two groups; this finding corroborates similar results from prior studies (Ahola et al., 2006; Lindblom et al., 2006; Llorent \& Ruiz-Calzado, 2016; Rožman et al., 2019). This may be because older employees face higher job demands and responsibilities; also, boredom can play a considerable role over time. Similarly, the CWB scores were significantly vary based on age; older employees are more likely to participate in CWB than the other two age groups. This is inconsistent with the results of (Peng, 2012; Ugwu et al., 2017), which observed that older employees are less likely to engage in CWB.

In contrast, (González-Navarro et al., 2018; Ying \& Cohen, 2018) found no differences in CWB based on age; young and old employees display equal chances to en- 
gage in deviant behavior. This might be because most of the training programs usually target younger employees, making the older employees feel that the organization neglects them. Besides, the banking sector framework has experienced profound shifts (e.g., online banking), which led to intensifying the competition between young and older employees. Another possible explanation is that when approaching retirement age, employees begin to develop a feeling that there is nothing to lose compared to younger employees and the difficulty in finding jobs.

The present study also highlights significant marital status differences in the exhaustion dimension of job burnout; single employees' manifest lower levels of exhaustion than divorced co-workers, which consistent with the results of (Ahola et al., 2006) and partially with the results of (Llorent \& Ruiz-Calzado, 2016) who observed that only depersonalization levels differ significantly according to marital status. Contrary to the current study results ( $\mathrm{Wu}$ et al., 2019; Mahmoudi et al., 2020) reported that marital status does not affect job burnout. Also, CWB scores significantly differ based on marital status; divorced employees are more likely to display deviant behavior than those married and single co-workers. This is incompatible with (Baysal et al., 2020), who stated that the marital status variable does not create a variation in CWB.

With respect to education level, we found that education levels significantly influence job burnout and counterproductive work behavior. The results show that as educational achievement advances, so does job burnout and CWB. Therefore future studies on the relationship should consider the educations levels of the employees.

The hierarchical regression analysis results revealed that job burnout has a significant positive impact on CWB among the frontline employees in the Jordanian banking industry. More specifically, the results show that the two job burnout dimensions, exhaustion, and disengagement, contribute significantly and positively to CWB among the employees. Job burnout dimensions alone responsible for at least $20.7 \%$ of the variation in CWB of the bank employees.

The result of the current study supported with previous findings of (Ugwu et al., 2017), who reported a positive relationship between job burnout and CWB among nurses, (Banks et al., 2012) also found a positive association between job burnout and CWB among bank employees, (Cohen \& Diamant, 2017; Makhdoom et al., 2019) among teachers and ( Liang \& Hsieh, 2007; Shkoler \& Tziner, 2017; Lebrón et al., 2018) across occupations. The results partially supported the findings ( Liang \& Hsieh, 2007; Bolton et al., 2011), who reported a positive relationship between only depersonalization and CWB. One explanation for the positive relationship may be related to the fact that bank employees in Jordan experience stress as a result of long working hours, extensive contact with various types of clients, high job demands, and competition between the employees. Also, the employee's salary and the annual evaluation depend on the monthly target, a state that can overburden and consume them (Particularly for customer service employees, tellers, and branch managers). Therefore, the stress-inducing work environment can extend the means to evoke the feeling of exhaustion and disengagement and, thus, lead to deviant work behaviors.

Additionally, the exhaustion caused by employees' excessive work-load can drive them to feel indifferent about their customers and work. Exhaustion and disengagement can increase the chances of deviant work behavior, for example, complaining about work tasks, creating problems, talking about work inside and outside the workplace, and concentrating on cynical aspects of work, especially in the recent period where the banking sector was among the sectors that continued to operate during the quarantine period and the spread of coronavirus in Jordan. The study results indicate that the relationship between job burnout and work outcomes (CWB) should be taken into more consideration by the banking industry.

Accordingly, our study has several implications. Banks that wish their workers not to participate in deviant behavior should ensure that employees' work demands do not overstretch and deplete their resources. The bank management, along with the human resources department, could utilize burnout intervention strategies concentrated on changing the organization (Organizational-level intervention) (Lubbadeh, 2020), which focuses on reducing the mismatch between the employees and the organization (e.g., overload, fairness, role ambiguity) and stressor at the workplace, or individual-level strategies that improve the employees' ability to manage and cope with the workplace stressor. For example, strategies geared towards developing the employees' psychological capital (PsyCap) and emotional intelligence can provide the employees with the necessary skills to cope with work stress and abilities to effectively manage their emotions and behaviors (Dartey-baah et al., 2020). Human resource managers in banks should also perform and design practical training and coaching procedures to promote employees' mental and physical health; in addition, organizing more out of work activities (e.g., sporting events, annual party) to increase the employee's feelings of belonging to the organization.

The present investigation has some limitations that should be recognized. All study participants were employees of commercial banks in Jordan, and the study did not include employees of Islamic banks. Data have been collected mainly by self-reporting instruments that could induce common method bias. Furthermore, data were collected during the outbreak of the Coronavirus (COVID-19) and State of emergency in Jordan, which could have influenced the participants' responses because they were those who continued their work during this period.

Further studies are needed to explore better the relationship between job burnout and counterproductive work 
behavior. It would be interesting to carry on a comparative examination between the employees working in commercial and Islamic banks or comparison at the international level. A longitudinal design study for future research would contribute to explaining the relationships between job burnout and CWB. Future research should also compare the link using different burnout inventory, such as MBI-GS and the Burnout Measure (BM.). Future research should also examine the result of the study after the end of the pandemic.

\section{Literature}

Ahola, K., Honkonen, T., Isometsä, E., Kalimo, R., Nykyri, E., Koskinen, S., Aromaa, A., \& Lönnqvist, J. (2006). Burnout in the general population. Social Psychiatry and Psychiatric Epidemiology, 41(1), 11-17. https://doi.org/10.1007/s00127-005-0011-5

Al-Asadi, J., Khalaf, S., Al-Waaly, A., Abed, A., \& Shami, S. (2018). Burnout among primary school teachers in Iraq: prevalence and risk factors. East Mediterr Health Journal, 24(3), 262-268. https://doi. org/10.26719/2018.24.3.262

Amigo, I., Asensio, E., Menéndez, I., Redondo, S., \& Ledesma, J. A. (2014). Working in direct contact with the public as a predictor of burnout in the banking sector. Psicothema, 26(2), 222-226. https://doi.org/10.7334/ psicothema2013.282

Armon, G. (2009). Do burnout and insomnia predict each other's levels of change over time independently of the job demand control - support (JDC - S) model?. Stress and Health, 25(4), 333-342. https://doi.org/10.1002/ smi.1266

Bakker, A. B., Demerouti, E., \& Verbeke, W. (2004). Using the Job Demands-Resources Model to Predict Burnout and Performance. Human Resource Management, 43(1), 83-104. https://doi.org/10.1002/hrm.20004

Banks, G. C., Whelpley, C. E., Oh, I., \& Shin, K. (2012). (How) are emotionally exhausted employees harmful? International Journal of Stress Management, 19(3), 198-216. https://doi.org/10.1037/a0029249

Baysal, C., Yangil, F. M., \& Sevim, Ş. (2020). Analysis of the relationship between organizational commitment and counterproductive work behaviour on academicians. Serbian Journal of Management, 15(1), 143157. https://doi.org/10.5937/SJM15-18502

Bennett, R. J., \& Robinson, S. L. (2000). Development of a Measure of Workplace Deviance. Journal of Applied Psychology, 85(3), 349-360. https://doi.org/10. I037//0021-9010.85.3.349

Berry, C. M., Carpenter, N. C., \& Barratt, C. L. (2012). Do Other-Reports of Counterproductive Work Behavior Provide an Incremental Contribution Over Self-Reports? A Meta-Analytic Comparison. Journal of Applied Psychology, 97(3), 613-636. https://doi. org/10.1037/a0026739

Bolton, L. R., Harvey, R. D., Grawitch, M. J., \& Barber, L. K. (2011). Counterproductive Work Behaviours in Response to Emotional Exhaustion : A Moderated Mediational Approach. Stress and Health, 28(3), 222233. https://doi.org/10.1002/smi.1425

Cohen, A. (2016). Are they among us? A conceptual framework of the relationship between the dark triad personality and counterproductive work behaviors (CWBs). Human Resource Management Review, 26(1), 69-85. https://doi.org/10.1016/j.hrmr.2015.07.003

Cohen, A., \& Diamant, A. (2017). The role of justice perceptions in determining counterproductive work behaviors. International Journal of Human Resource Management, 30(20), 2901-2924. https://doi.org/10.1080 /09585192.2017.1340321

Cruz-Santiago, J. M., Vélez-Vega, A., \& Vélez -Alvarado, R. A. (2020). The Predictors of Job Burnout on Job Boredom in a sample of workers in the banking industry of Puerto Ricol. Informes Psicológicos, 20(1), 167-181. https://doi.org/10.18566/infpsic.v20n1a11

Dartey-baah, K., Quartey, S. H., \& Osafo, G. A. (2020). Examining occupational stress, job satisfaction and gender difference among bank tellers: evidence from Ghana. International Journal of Productivity and Performance Management, 69(7), 1437-1454. https://doi. org/10.1108/IJPPM-07-2019-0323

De Clercq, D., Haq, I. U., \& Azeem, M. U. (2019). Time-related work stress and counterproductive work behavior: Invigorating roles of deviant personality traits. Personnel Review, 48(7), 1756-1781. https:// doi.org/10.1108/PR-07-2018-0241

Demerouti, E., Bakker, A. B., \& Leiter, M. (2014). Burnout and job performance: The moderating role of selection, optimization, and compensation strategies. Journal of Occupational Health Psychology, 19(1), 96-107. https://doi.org/10.1037/a0035062

Demerouti, E., Bakker, A. B., \& Schaufeli, W. B. (2001). The Job Demands-Resources Model of Burnout. Journal of Applied Psychology, 86(3), 499-512. https://doi. org/10.1037//0021-9010.86.3.499

Demerouti, E., Bakker, A. B., Vardakou, I., \& Kantas, A. (2003). The Convergent Validity of Two Burnout Instruments : A Multitrait-Multimethod Analysis. European Journal of Psychological Assessment, 19(1), 12-23. https://doi.org/10.1027//1015-5759.19.1.12

Demerouti, E., Mostert, K., \& Bakker, A. B. (2010). Burnout and Work Engagement: A Thorough Investigation of the Independency of Both Constructs. Journal of Occupational Health Psychology, 15(3), 209-222. https://doi.org/10.1037/a0019408

Demerouti, E., Verbeke, W. J. M. I., \& Bakker, A. B. (2005). Exploring the relationship between a multidimensional and multifaceted burnout concept and self-rated per- 
formance. Journal of Management, 31(2), 186-209. https://doi.org/10.1177/0149206304271602

Dyrbye, L. N., Shanafelt, T. D., Johnson, P. O., Johnson, L. A., Satele, D., \& West, C. P. (2019). A cross-sectional study exploring the relationship between burnout, absenteeism, and job performance among American nurses. BMC Nursing, 18(1), 1-8. https://doi.org/10.1186/ s12912-019-0382-7

Giorgi, G., Arcangeli, G., Perminiene, M., Lorini, C., Ariza-montes, A., Fiz-perez, J., Fabio, A. Di, \& Mucci, N. (2017). Work-Related Stress in the Banking Sector : A Review of Incidence, Correlated Factors, and Major Consequences. Frontiers in Psychology, 8(2166), 1-17. https://doi.org/10.3389/fpsyg.2017.02166

González-Navarro, P., Zurriaga-Llorens, R., Olateju, A. T., \& Llinares-Insa, L. I. (2018). Envy and counterproductive work behavior: The moderation role of leadership in public and private organizations. International Journal of Environmental Research and Public Health, 15(7), 1455. https://doi.org/10.3390/ijerph15071455

Halbesleben, J. R. B., \& Demerouti, E. (2005). The construct validity of an alternative measure of burnout: Investigating the English translation of the Oldenburg Burnout Inventory. Work \& Stress, 19(3), 208-220. https://doi.org/10.1080/02678370500340728

Jakada, M. B., Kassim, S. I., Hussaini, A., Mohammed, A. I., \& Rabi 'u, A. (2020). Construct Validity and Reliability of Individual Work Performance Questionnaire among Academic and Non-Academic Employees. Ilorin Journal of Human Resource Management, 4(2), 155-164.

Kleinbaum, D. G., Kupper, L. L., \& Muller, K. E. (1988). Applied Regression Analysis and Other Multivariable Methods. PWS Publishing Co.

Koopmans, L. (2015). Individual Work Performance Questionnaire instruction manual. TNO Innovation for Life - VU University Medical Center.

Koopmans, L., Bernaards, C. M., Hildebrandt, V. H., Lerner, D., De Vet, H. C. W., \& Van Der Beek, A. J. (2016). Cross-cultural adaptation of the Individual Work Performance Questionnaire. Work, 53(3), 609619. https://doi.org/10.3233/WOR-152237

Lackritz, J. R. (2004). Exploring burnout among university faculty : incidence, performance, and demographic issues. Teaching and Teacher Education, 20(7), 713729. https://doi.org/10.1016/j.tate.2004.07.002

Laschinger, H. K. S., \& Fida, R. (2014). A time-lagged analysis of the effect of authentic leadership on workplace bullying, burnout, and occupational turnover intentions. European Journal of Work and Organizational Psychology, 23(5), 739-753. https://doi.org/10.1080/1359432X.2013.804646

Lebrón, M., Tabak, F., Shkoler, O., \& Rabenu, E. (2018). Counterproductive Work Behaviors toward Organization and Leader-Member Exchange: The Mediating
Roles of Emotional Exhaustion and Work Engagement. Organization Management Journal, 15(4), 159173. https://doi.org/10.1080/15416518.2018.1528857

Leiter, M. P., Hakanen, J. J., Ahola, K., Toppinen-Tanner, S., Koskinen, A., \& Väänänen, A. (2013). Organizational predictors and health consequences of changes in burnout: A 12-year cohort study. Journal of Organizational Behavior, 34(9), 959-973. https://doi. org/10.1002/job

Liang, S.-C., \& Hsieh, A.-T. (2007). Burnout and workplace deviance among flight attendants in Taiwan. Psychological Reports, 101(2), 457-468. https://doi.org/ pr0.101.2.457-468

Lindblom, K. M., Linton, S. J., Fedeli, C., \& Bryngelsson, I. (2006). Burnout in the Working Population: Relations to Psychosocial Work Factors. International Journal of Behavioral Medicine, 13(1), 51-59. https:// doi.org/10.1207/s15327558ijbm1301_7

Llorent, V. J., \& Ruiz-Calzado, I. (2016). Burnout and its relation to sociodemographic variables among education professionals working with people with disabilities in Córdoba (Spain). Ciencia e Saude Coletiva, 21(10), 3287-3295. https://doi.org/10.1590/1413812320152110.00732015

Lubbadeh, T. (2020). Job Burnout: A General Literature Review. International Review of Management and Marketing, 10(3), 7-15. https://doi.org/10.32479/ irmm.9398

Mahmoudi, S., Barkhordari-sharifabad, M., Pishgooie, A., Atashzadeh-Shoorideh, F., \& Lotfi, Z. (2020). Burnout among Iranian nurses : a national survey. $B M C$ Nursing, 19(1), 1-9. https://doi.org/10.1186/s12912020-00461-7

Makhdoom, I. F., Atta, M., \& Malik, N. I. (2019). Counterproductive Work Behaviors as an Outcome of Job Burnout among High School Teachers. Bulletin of Education and Research, 41(2), 79-92.

Maslach, C. (2006). Understanding job burnout. In A. M. Rossi, P. L. Perrewe, \& S. L. Sauter (Eds.), stress and quality of working life current perspectives in occupational health (pp. 37-51). Greenwich: Information Age Publishing.

Maslach, C., Schaufeli, W. B., \& Leiter, M. P. (2001). Job Burnout. Annual Review of Psychology, 52(1), 397422. https://doi.org/10.1146/annurev.psych.52.1.397

Mulki, J. P., Jaramillo, F., \& Locander, W. B. (2006). Emotional exhaustion and organizational deviance: Can the right job and a leader's style make a difference? Journal of Business Research, 59(12), 1222-1230. https:// doi.org/10.1016/j.jbusres.2006.09.001

Peng, H. (2012). Counterproductive Work Behavior Among Chinese Knowledge Workers. International Journal of Selection and Assessment, 20(2), 119-138. https://doi.org/10.1111/j.1468-2389.2012.00586.x

Prusik, M., \& Szulawski, M. (2019). The Relationship 
Between the Dark Triad Personality Traits, Motivation at Work, and Burnout among HR Recruitment Workers. Front. Psychol, 10(1290), 1-12. https://doi. org/10.3389/fpsyg.2019.01290

Rehman, W. U., Yousaf, S., \& Naeem, H. (2015). Impact of burnout on employees ' performance : An analysis of banking industry. World Review of Entrepreneurship, Management and Sustainable Development, 11(1), 88105. https://doi.org/10.1504/WREMSD.2015.066980

Robinson, S. L., \& Bennett, R. J. (1995). A Typology of Deviant Workplace Behaviors: A Multidimensional Scaling Study. Academy of Management Journal, 38(2), 555-572. https://doi.org/10.2307/256693

Rotundo, M., \& Sackett, P. R. (2002). The relative importance of task, citizenship, and counterproductive performance to global ratings of job performance: a policy-capturing approach. The Journal of Applied Psychology, 87(1), 66-80. https://doi.org/10.1037/00219010.87.1.66

Rožman, M., Grinkevich, A., \& Tominc, P. (2019). Occupational Stress, Symptoms of Burnout in the Workplace, and Work Satisfaction of the Age-diverse Employees. Organizacija, 52(1), 46-59. https://doi. org/10.2478/orga-2019-0005

Sackett, P. R., \& DeVore, C. J. (2002). Counterproductive behaviors at work. In N. Anderson, D. S. Ones, H. K. Sinangil, \& C. Viswesvaran (Eds.), Handbook of industrial, work and organizational psychology (Vol. 1., pp. 145-16). Sage Publications Ltd.

Shkoler, O., \& Tziner, A. (2017). The mediating and moderating role of burnout and emotional intelligence in the relationship between organizational justice and work misbehavior. Journal of Work and Organizational Psychology, 33(2), 157-164. https://doi.org/10.1016/j. rpto.2017.05.002

Smoktunowicz, E., Baka, L., Cieslak, R., Nichols, C. F., Benight, C. C., \& Luszczynska, A. (2015). Explaining Counterproductive Work Behaviors Among Police Officers: The Indirect Effects of Job Demands Are Mediated by Job Burnout and Moderated by Job Control and Social Support. Human Performance, 28(4), 332350. https://doi.org/10.1080/08959285.2015.1021045

Socorro, M. do, Valente, S., Lopes, C. S., Pastor-Valero, M., \& Menezes, P. R. (2016). Psychosocial Work Conditions and Burnout Among Brazilian Bank Employees : A Cross-Sectional Study. Annals of Occupational Hygiene, 60(5), 567-850. https://doi.org/10.1093/annhyg/mew013

Spector, P. E., \& Fox, S. (2005). The stressor-emotion model of counterproductive work behavior. In P. E. Spector \& S. Fox (Eds.), Counterproductive work behavior: Investigations of actors and targets (pp. 151174). American Psychological Association. https://doi. org/10.1037/10893-007

Spector, P. E., Fox, S., Penney, L. M., Bruursema, K., Goh,
A., \& Kessler, S. (2006). The dimensionality of counterproductivity: Are all counterproductive behaviors created equal ? Journal of Vocational Behavior, 68(3), 446-460. https://doi.org/10.1016/j.jvb.2005.10.005

Tarcan, G. Y., Tarcan, M., \& Top, M. (2017). An analysis of relationship between burnout and job satisfaction among emergency health professionals. Total Quality Management and Business Excellence, 28(11-12), 1339-1356. https://doi.org/10.1080/14783363.2016.1 141659

Uchenna, C. O. (2013). Counterproductive Work Behavior among Employees in Emotionally Demanding Jobs: The Roles of Perceived Organizational Support, Job Burnout, and Age. Nigerian Journal of Applied Behavioural Sciences, 1, 105-114.

Ugwu, L. I., Enwereuzor, I. K., Fimber, U. S., \& Ugwu, D. I. (2017). Nurses' burnout and counterproductive work behavior in a Nigerian sample : The moderating role of emotional intelligence. International Journal of Africa Nursing Sciences, 7, 106-113. https://doi.org/10.1016/j.ijans.2017.11.004

Vaamonde, J. D., Omar, A., \& Salessi, S. (2018). From Organizational Justice Perceptions to Turnover Intentions: The Mediating Effects of Burnout and Job Satisfaction. Europe's Journal of Psychology, 14(3), 55-570. https://doi.org/10.5964/ejop.v14i3.1490

Wen, B., Zhou, X., Hu, Y., \& Zhang, X. (2020). Role Stress and Turnover Intention of Front-Line Hotel Employees : The Roles of Burnout and Service Climate. Front. Psychol, 11(36), 1-13. https://doi.org/10.3389/ fpsyg.2020.00036

Wu, G., Hu, Z., \& Zheng, J. (2019). Role Stress, Job Burnout, and Job Performance in Construction Project Managers : The Moderating Role of Career Calling. Environmental Research and Public Health, 19(13), 2394. https://doi.org/10.3390/ijerph16132394

Ying, L., \& Cohen, A. (2018). Dark triad personalities and counterproductive work behaviors among physicians in China. International Journal of Health Planning and Management, 33(4), e985-e998. https://doi. org/10.1002/hpm.2577

Tareq Lubbadeh (https://orcid.org/0000-0002-81188775 ) is a Ph.D. candidate in business administration at the University of Pécs, Hungary. He holds an MBA degree from Al- Balqa' Applied University (BAU), Amman, Jordan. In his doctoral research, he focuses on the relation between job burnout and employee performance. He has a genuine interest in combining the art and science of psychology with useful and practical business applications to improve the work environment. 


\section{Appendix A. List of Measurement Items: Supply Chain Dynamic Capabilities}

\section{The Oldenburg Burnout Inventory (OLBI) \\ Disengagement items}

D1: "I always find new and interesting aspects in my work."

D2: "I find my work to be a positive challenge."

D3: "This is the only type of work that I can imagine myself doing."

D4: "I feel more and more engaged in my work."

\section{Disengagement reversed items}

DR1: "It happens more and more often that I talk about my work in a negative way."

DR2: "Lately, I tend to think less at work and do my job almost mechanically."

DR3: "Over time, one can become disconnected from this type of work."

DR4: "Sometimes, I feel sickened by my work tasks."

\section{Exhaustion items}

EX1: "I can tolerate the pressure of my work very well."

EX2: "After working, I have enough energy for my leisure activities."

EX3: "Usually, I can manage the amount of my work well."

EX4: "When I work, I usually feel energized."

Exhaustion reversed items

EXR1: "There are days when I feel tired before I arrive at work."

EXR2: "After work, I tend to need more time than in the past in order to relax and feel better."

EXR3: "During my work, I often feel emotionally drained."

EXR4: "After my work, I usually feel worn out and weary."

Counterproductive work behavior scale (CWB).

CWB1: "I complained about minor work-related issues at work."

CWB2: "I made problems at work bigger than they were."

CWB3: "I focused on the negative aspects of situation at work instead of the positive aspects."

CWB4: "I talked to colleagues about the negative aspects of my work."

CWB5: "I talked to people outside the organization about the negative aspects of my work." 